\title{
Creep and plasticity of glacier ice: a material science perspective
}

\author{
Paul DUVAL, Maurine MONTAGNAT, Fanny GRENNERAT, Jerome WEISS, \\ Jacques MEYSSONNIER, Armelle PHILIP
}

\author{
Laboratoire de Glaciologie et Géophysique de I'Environnement, CNRS/Université Joseph Fourier - Grenoble I, \\ 54 rue Molière, BP 96, 38402 Saint-Martin-d'Hères Cedex, France \\ E-mail: duval@Igge.obs.ujf-grenoble.fr
}

\begin{abstract}
Major advances in understanding the plasticity of ice have been made during the past 60 years with the development of studies of the flow of glaciers and, recently, with the analysis of deep ice cores in Antarctica and Greenland. Recent experimental investigations clearly show that the plastic deformation of the ice single crystal and polycrystal is produced by intermittent dislocation bursts triggered by long-range interaction of dislocations. Such dislocation avalanches are associated with the formation of dislocation patterns in the form of slip lines and slip bands, which exhibit long-range correlations and scale invariance. Long-range dislocation interactions appear to play an essential role in primary creep of polycrystals and dynamic recrystallization. The large plastic anisotropy of the ice crystal is at the origin of large strain and stress heterogeneities within grains. The use of fullfield approaches is now a compulsory proceeding to model the intracrystalline heterogeneities that develop in polycrystals. Ice is now highly regarded among the materials science community. It is considered a model material for understanding deformation processes of crystalline materials and polycrystal modeling.
\end{abstract}

\section{INTRODUCTION}

Physicists have long been interested in the plasticity of ice. The first experiments seem to have been performed by McConnel and Kidd (1888) who showed that single crystals of ice plastically deformed like a pack of cards, and observed that the rate of deformation increased with time. The idea of the viscous behaviour of glacier ice was expressed by Rendu (1840) and studied by L. Agassiz and J.D. Forbes between 1840 and 1851 (Tyndall, 1873).

More recently, interest in research on the plasticity of ice was significantly increased by the joint meeting of the British Glaciological Society (BGS) and the Institute of Metals held in Cambridge, UK, on 29 April 1948. Dr G. Seligman, past president of the Institute of Metals and awarded the Seligman Crystal in 1963, was the chairman of this meeting (BGS, 1949). E. Orowan and M.F. Perutz, both of the Cavendish Laboratory, Cambridge, opened the discussion on 'The flow of ice and other solids'. Orowan is well known for his work on the plasticity of metals, especially on the role of dislocations in the plasticity of crystalline solids (Orowan, 1940). Perutz, winner of the Nobel Prize in chemistry, was the PhD supervisor of J.W. Glen. Glen (1952) and Nye (1952) showed that the viscosity of ice decreases with increasing stress, i.e. the creep of ice is non-Newtonian, as assumed by BGS (1949). It is worth noting that, at this time, most new ideas on ice plasticity came from the materials science community, while glaciology research had just begun.

Progress in understanding the plasticity of ice has since been achieved by creep experiments performed on ice single crystals and polycrystals. Evidence of easy basal slip was first shown by McConnel and Kidd (1888) and later by many authors (Glen and Perutz, 1954; Griggs and Coles, 1954; Steinemann, 1954; Higashi, 1967; Jones and Glen 1969; see Weertman, 1973, for a review). The flow law relating strain rate to the applied stress for basal slip in single crystals is a power law with a stress exponent of $\sim 2$ (Higashi and others, 1965; Jones and Glen, 1969; Mellor and Testa, 1969). Using the famous Orowan's relation and measurements of the velocity of dislocations on the basal plane (Petrenko and Whitworth, 1999), the density of mobile dislocations could be determined.

Many creep experiments have been performed on isotropic freshwater ice at relatively high temperature in order to determine the flow law of glacier ice (Glen, 1955; Steinemann, 1958). Ice, like many other materials, exhibits three stages: an initial decelerating primary creep, a quasistationary secondary creep and finally a tertiary creep with a higher strain rate. A description and results of such experiments are provided by Jacka (1984). The flow law for isotropic ice is also a power law, but with a stress exponent of $\sim 3$ for an equivalent stress higher than 0.1-0.2 MPa (Barnes and others, 1971; Budd and Jacka, 1989). The behavior of ice at low stresses has been the subject of numerous studies over several decades. The difficulty of obtaining reliable data at strain rates lower than $10^{-10} \mathrm{~s}^{-1}$ accounts for the contradictory results. There is a clear indication of decrease in the stress exponent as soon as equivalent stresses are $<0.1 \mathrm{MPa}$ (Schulson and Duval, 2009).

The effect of dynamic recrystallization and fabrics (or textures in materials science) on the behavior of ice is significant when looking at glacier dynamics. The effect of fabrics is now taken into account in ice-sheet flow modeling (Martin and others, 2009; Ma and others, in press). Conditions for the occurrence of secondary and tertiary creep in polar ice sheets, however, are not very clearly determined. This deficiency comes from lack of knowledge of the physical conditions for the occurrence of continuous (rotation) or discontinuous (migration) recrystallization (Alley, 1992; Schulson and Duval, 2009). Analysis of the effect of grain size, particles, impurities and water content on the ice viscosity is provided by Paterson (1991) and Schulson and Duval (2009) for glacier ice and by Durham and others (1992) for ice of the outer Solar System. 
These experimental results alone do not permit identification of the physical processes involved in the deformation of ice. As in metals, the gliding of dislocations on crystallographic planes is the main mechanism of the plastic deformation. Purely diffusional processes are invoked to explain the behavior of polycrystalline ice at low stresses, but the occurrence of such processes in ice is not proven. The $n=3$ stress exponent found in polycrystalline ice could, however, be explained by dislocation climb, which involves the diffusion of point defects (Weertman, 1983).

Dislocation-mediated plasticity is commonly considered as a regular process occurring homogeneously in space and smoothly in time. This viewpoint was challenged many years ago by Nakaya (1958) who performed bending experiments on ice single crystals. Traces of basal slip lines were made visible by shadow photography. Information about the temporal behavior of plastic flow has been inferred more recently from acoustic emission measurements on ice single crystals by Weiss and Grasso (1997). These experiments performed during deformation showed that plastic deformation proceeds through an intermittent dynamics. The intermittency of dislocation activity is associated with spatial localization because each strain burst appears to correspond to the formation of a slip line. Both acoustic emission experiments and analyses of the distribution of slip lines by X-ray topography on ice single crystals revealed scale invariance with power-law size distribution for strain bursts and scale-invariant (fractal) dislocation arrangements over several decades (Miguel and others, 2001; Weiss and Marsan, 2003; Montagnat and others, 2006). Dislocations move cooperatively in groups rather than individually. This collective behavior is driven by long-range elastic dislocation interactions. In polycrystals, grain boundaries act as barriers to the dynamic propagation of dislocation avalanches and hinder this scale-free pattern (Richeton and others, 2005b). These scale-invariant properties can raise difficulties for the use of average quantities (e.g. dislocation density) or homogenization techniques (Weiss and Montagnat, 2007).

Understanding of the dynamics of interacting dislocations, still in its infancy, is of the highest importance for the behavior of crystalline materials. Following Mott (1953), primary creep in polycrystalline ice obeys the Andrade creep law in $t^{1 / 3}$. It can be analyzed by considering the longrange dislocation interactions and kinematic hardening induced by the strong visco-plastic anisotropy of the ice crystal (Louchet and Duval, 2009).

Computation of the mechanical behavior and texture development in polycrystalline materials using micro-macro techniques is now a standard approach in materials and geological science. The limitations of such approaches are related to the difficulty of considering stress and strain intragranular heterogeneities, especially in anisotropic materials. Full-field formulation based on fast Fourier transform (FFT) has recently been used to predict the micromechanical fields in polycrystalline ice (Lebensohn and others, 2009). The very large visco-plastic anisotropy of the ice crystal induces strong deformation gradients and strain localization inside grains (Mansuy, 2001). A digital image correlation technique was recently used to record continuously the intragranular strain field during creep tests on columnar ice (Grennerat and others, in press). One objective of these experimental measurements is to validate a full-field FFT model treating the elasto/visco-plasticity, required to analyze transient effects.
Considering these recent experimental and modeling results, the contribution of the ice physics community to the theoretical understanding of the mechanical behavior of materials is significant. With the large anisotropy of the ice crystal, ice is now considered a model material for validating theoretical assumptions made in mechanical models (Lebensohn and others, 2007). Ice lends itself to experimental analysis because of its transparency to visible light and X-rays, the ease with which large single crystals and two-/three-dimensional polycrystals with various grain sizes can be grown, the possibility of performing mechanical tests near the melting point and the preponderance of dislocations accommodating orientation gradients (excess dislocations) on forest dislocations (statistically stored dislocations) (Nye, 1953; Ashby, 1970).

This paper summarizes the main mechanical properties of the single crystal and the polycrystal. We show that longrange dislocation interactions play a fundamental role in the plasticity of ice. Special emphasis is placed on the development of stress and strain-rate heterogeneities inside grains during primary creep. The role of long-range internal stresses in grain nucleation during discontinuous recrystallization is also discussed.

Following the seminal and fruitful discussions between glaciologists and metal physicists during the joint meeting held in Cambridge in 1948, we wish to show the high interest in studying the plasticity of ice for both glaciology and materials science studies.

\section{CREEP AND PLASTICITY OF THE SINGLE CRYSTAL}

\subsection{Slip patterns and intermittent flow}

Optical observations of basal slip lines by Nakaya (1958) have been widely used to show that basal slip dominates the ice plastic activity. Basal slip takes place through the motion of basal dislocations with the $a / 3\langle 11 \overline{2} 0\rangle$ Burgers vector. Basal dislocations gliding on basal planes are found to be far more numerous than those propagating on non-basal planes (Petrenko and Whitworth, 1999).

The creep response reveals a two-stage behavior with a transient stage during which strain rate increases with time due to dislocation multiplication (Jones and Glen, 1969). From Higashi and others (1965), stationary creep is observed for a strain of $\sim 0.2$. During this second stage, strain rate is related to stress by a power law with a stress exponent of $\sim 2$ (Fig. 1).

Plastic flow on microscopic and mesoscopic scales proceeds in a heterogeneous and intermittent manner. Long-range interaction of dislocations leads to localization and intermittency. Dislocations move cooperatively in groups of spatially correlated slip planes rather than individually (Zaiser, 2006). The most common method for studying the spatial heterogeneity of slip and dislocation patterns is to analyze the surface of deformed samples. Figure 2 shows basal slip lines in a large deformed ice single crystal imbedded in an ice matrix of very small grains, as observed by optical methods.

X-ray diffraction appears to be well adapted for bulk observation since ice is transparent to X-rays. An example of the distribution of dislocations - those that accommodate the torsion strain - along the axis of an ice sample deformed in torsion is shown in Figure 3 (Chevy and others, 2010). The $c$-axis being parallel to the torsion axis, 


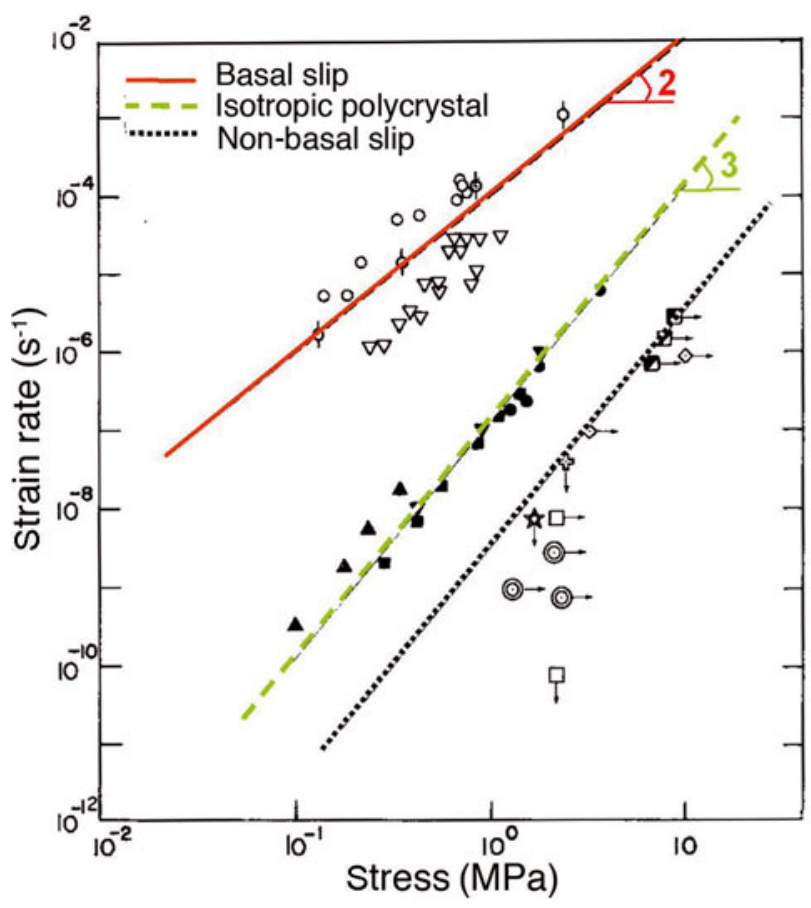

Fig. 1. Creep data for single and isotropic polycrystals at $-10^{\circ} \mathrm{C}$ (from Duval and others, 1983). Arrows for non-basal slip indicate that strain rate (or axial stress) should be lower (or higher).

the distortion of prismatic planes associated with torsion is accommodated with basal screw dislocations. The diffracted intensity along the torsion axis is directly related to the density of screw dislocations that accommodate the torsion. The heterogeneous distribution of dislocations is clearly shown. The power spectrum of the dislocation distributions, calculated from the FFT of the signal, is characterized by a scaling law, $P(f)=f^{-\mu}$ (Montagnat and others, 2006), over a length scale range larger than several millimeters. Such a property indicates scale invariance of the diffracted intensity, and hence of the dislocation density distribution along the torsion axis. The exponent of the power spectrum, $\mu$, is 0.95 for this sample. This scale invariance implies that the dislocation density distribution is spatially correlated on a large scale. This indicates longdistance interactions between dislocations (Weiss and Marsan, 2003). These observations question the pertinence of widely used concepts such as the distance between slip lines and slip bands. This collective motion of dislocations is not restricted to ice but is a general feature of crystal plasticity (Zaiser and Seeger, 2002).

The collective motion of dislocations is associated with intermittent strain bursts. Although the existence of intermittent plastic strain bursts has been known for many years, a statistical characterization was first performed by acoustic emission experiments in ice single crystals by Weiss and Grasso (1997). It was shown that the size distribution of energy bursts follows a power law over several decades (Fig. 4; Miguel and others, 2001). The individual motion of dislocations, as analyzed from X-ray topography measurements on thin samples with low dislocation density (Petrenko and Whitworth, 1999), could not represent the real situation for the deformation of the ice crystal. The dislocation velocity during avalanches is much higher than that of isolated dislocations (Mendelson, 1963). Unfortunately,

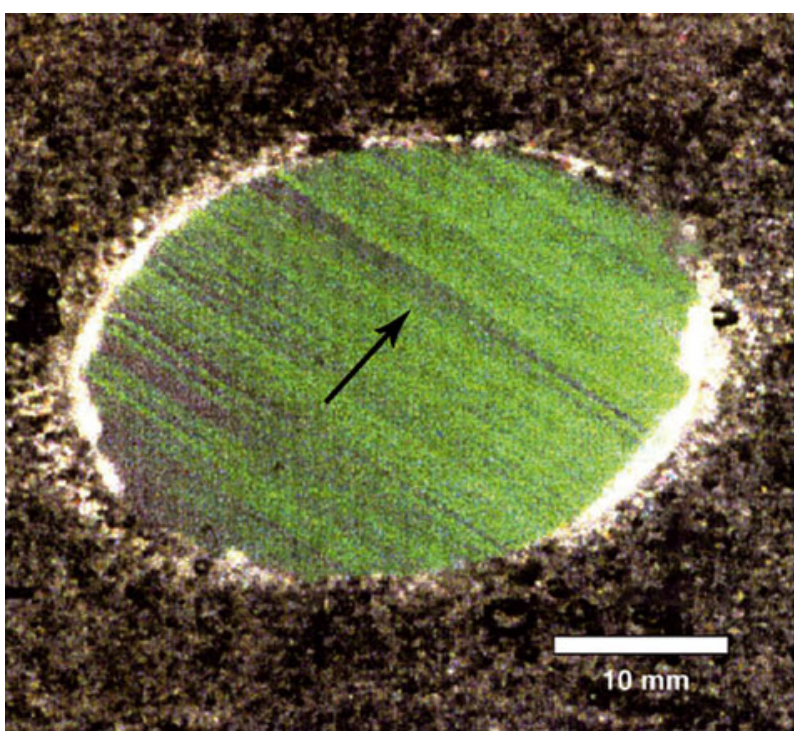

Fig. 2. Photograph of a sample deformed in uniaxial compression after a deformation of $6.3 \times 10^{-2}$. The arrow indicates the $c$-axis direction. The monocrystalline inclusion was embedded in an isotropic matrix of fine grains (from Mansuy, 2001).

direct measurements during deformation are not possible. This power-law distribution of dislocation avalanches and the spatial heterogeneity of slip are both related to longrange dislocation interactions. These measurements of acoustic emissions on ice crystals are frequently used by the material science community when discussing the scalefree intermittent flow in crystals (Dimiduk and others, 2006; Zaiser, 2006).

\subsection{Rate-controlling processes for basal slip}

The continuous increase of strain rate during creep is related to the multiplication of mobile dislocations by climb or cross-slip. Multiplication of basal screw dislocations by double cross-slip was suggested by Montagnat and others (2006) to explain the deformation of ice single crystals



Fig. 3. Dislocation density distribution along the torsion axis after a strain of 56\% (from Chevy and others, 2010). Acta Materialia by American Institute of Mining, Metallurgical, and Petroleum Engineers. Reproduced with permission of Pergamon via Copyright Clearance Center. 




Fig. 4. Distribution of acoustic energy bursts recorded in ice single crystals under creep tests at $-10^{\circ} \mathrm{C}$. Inset is a typical recorded acoustic signal (from Miguel and others, 2001). Nature by Nature Publishing Group. Reproduced with permission of Nature Publishing Group via Copyright Clearance Center.

deformed in torsion. The dissociation of basal screw dislocations into widely extended partial dislocations should make the cross-slip process difficult (Petrenko and Whitworth, 1999). These dislocations must first constrict over a short distance to allow this process to begin. From Duesbery (1998), cross-slip is possible at all partial separations, provided that the stress is sufficiently large. In summary, the plasticity of single crystals of ice is governed by shortand long-range interactions between dislocations and not by lattice resistance. Multiplication of dislocations can be induced by both dislocation climb and cross-slip.

\section{CREEP AND PLASTICITY OF THE ICE POLYCRYSTAL}

Knowledge of the physical processes that occur during viscous deformation of freshwater polycrystalline ice is required to establish constitutive laws between the macroscopic variables of strain rate, strain, stress and temperature. There are strong arguments for considering basal slip as the main deformation process in the large range of equivalent stresses involved in glaciers and polar ice sheets. However, basal slip alone cannot accommodate the deformation. Other deformation modes must be invoked such as slip on non-basal planes, climb and cross-slip of basal dislocations. The large difference in behavior between the polycrystal and single crystals oriented for basal slip (Fig. 1) suggests that strain rate in polycrystals is not controlled by basal slip. On first loading, the stress state is uniform. As creep relaxes the shear stress on the basal plane, load is transferred to the harder non-basal systems. An increasingly non-uniform internal stress field develops. These internal stresses are long-range and oppose further deformation, i.e. they give directional or kinematic hardening. Long-range dislocation interactions are thus essential to explain the plastic flow of polycrystals (Duval and others, 1983).

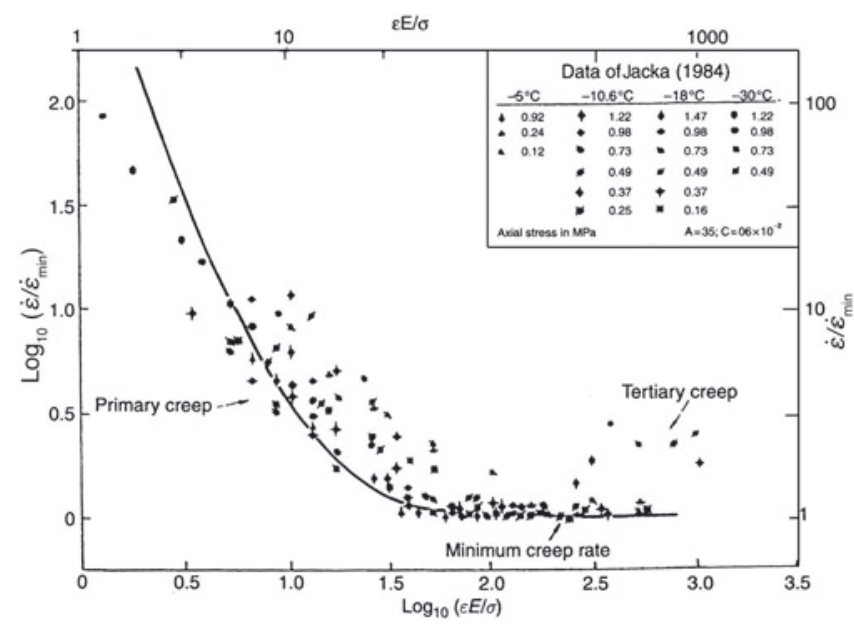

Fig. 5. Strain rate plotted against strain using reduced variables for isotropic ice (from Ashby and Duval, 1985). Cold Regions Science and Technology by Elsevier BV. Reproduced with permission of Elsevier BV via Copyright Clearance Center.

Reviews of the creep behavior of polycrystalline ice are provided by Weertman (1973, 1983), Duval and others (1983), Budd and Jacka (1989), Schulson and Duval (2009) and Cuffey and Paterson (2010).

\subsection{Long-range internal stresses and transient creep}

Andrade's law in $t^{1 / 3}$ for primary creep appears to be observed in many crystalline materials, in polymers and recently in ordinary paper (Rosti and others, 2010), leading to the conclusion that this should be explained from general principles, independently of materials properties.

Following the first theoretical explanation of Orowan (1946) and Mott (1953), Andrade's law should derive from a non-equilibrium phase transition with long-range interactions. For ice, owing to long-range dislocation interactions, the unlocking of a dislocation from an obstacle requires the escape by climb or cross-slip of a number of dislocations (Louchet and Duval, 2009). With this concept of load shedding and mechanical cascades, the transient creep can be analyzed in terms of criticality (Miguel and others, 2002; Zaiser, 2006). Dislocation motion during transient creep also appears to be characterized by avalanches (Richeton and others, 2005), leading to the formation of slip lines and slip bands. However, in polycrystals, grain size sets the size of the largest avalanches; grain boundaries are obstacles to their propagation (Richeton and others, 2005a).

Based on creep data of Jacka (1984) obtained over a range of temperature and stress, a single master curve was obtained for polycrystalline ice (Fig. 5). The strain rate decreases by a factor of $>100$ during primary creep. The hardening is essentially kinematic or directional; it is responsible for the relatively large deformation recovered after unloading (Duval, 1978) that also occurs through dislocation avalanches (Richeton and others, 2005). Transient creep in ice was reproduced using an elasto/visco-plastic model and by introducing the progressive hardening of hard slip systems (Castelnau and others, 2008).

The development of intragranular strain heterogeneities during transient creep was analyzed on two-dimensional (2-D) columnar ice using a digital image correlation technique (Grennerat and others, in press). Preliminary 
results indicate that local strain can be up to six times the average strain $(\sim 1 \%)$ during transient creep. Deformation bands stretching out over several grains are oriented at $\sim 45^{\circ}$ from the compression axis, and the level of local deformation is not correlated with grain orientation.

\subsection{Long-range internal stresses and dynamic recrystallization}

During deformation at relatively high temperature, recrystallization may take place. Dynamic recrystallization can occur by several mechanisms and can be continuous or discontinuous (Guillopé and Poirier, 1979). During continuous recrystallization, sub-boundaries form as deformation proceeds, and high-angle boundaries may develop from the progressive misorientation of sub-boundaries. In this recrystallization regime, grain boundaries migrate in the same low-velocity regime as that associated with grain growth (Duval and others, 1983; Poirier, 1985). Continuous dynamic recrystallization occurs extensively in polar ice sheets (Alley, 1992; Thorsteinsson and others, 1997; de La Chapelle and others, 1998) and is commonly observed during the hot deformation of metal alloys (Humphreys and Hatherly, 1996). This recrystallization mechanism leads to textures similar to deformation textures.

Discontinuous recrystallization results from the rapid migration of grain boundaries between dislocation-free nuclei and deformed grains (Poirier, 1985). The grain boundary migration rate must be high in relation to the rate of accumulation of dislocations within the nucleus (Roberts and Ahlblom, 1978). In ice, the grain boundary migration rate is typically 100 times larger than during continuous recrystallization (Duval and Castelnau, 1995). Discontinuous recrystallization gives coarse and interlocking grains, and recrystallized grains are well oriented for the easy basal slip (Kamb, 1972; Duval, 1981; Jacka and Maccagnan, 1984). In the laboratory, such recrystallization textures form for a strain of $<10 \%$ (Jacka and Maccagnan, 1984). Recrystallization textures are stress-controlled and thus do not reflect the deformation history (Duval, 1981; Alley, 1992). This recrystallization process is the one that occurs in temperate glaciers and in ice sheets where temperature and stored energy are high enough. It corresponds to tertiary creep.

\section{Nucleation of recrystallization}

Recrystallization always proceeds from a deformed microstructure by the formation of nuclei and their growth. The driving force is the decrease of the stored energy within the embryo, but the formation of nuclei leads to additional interface energy. The total change in free energy, $\Delta g$, associated with the formation of a nucleus is given by

$$
\Delta g=\frac{4}{3} \pi r^{3}\left(\Delta g_{\mathrm{v}}\right)+4 \pi r^{2} \gamma_{\mathrm{gb}}
$$

where $r$ is the radius of the embryo, $\gamma_{\mathrm{gb}}$ is the grain boundary energy and $\Delta g_{v}$ is generally considered as the stored energy within the embryo.

The critical radius corresponding to the maximum of the free energy is given by

$$
r^{*}=2 \gamma_{\mathrm{gb}} / \Delta g_{\mathrm{v}} .
$$

For ice with a dislocation density of $10^{12} \mathrm{~m}^{-2}$, a relatively high value for polar ice sheets (Montagnat and Duval, 2000), $\Delta g_{\mathrm{v}}=300 \mathrm{~J} \mathrm{~m}^{-3}$ and $r^{*}=0.4 \mathrm{~mm}$; the free energy at the maximum is $\Delta g^{*}=4.8 \times 10^{-8} \mathrm{~J}$. In metals, the stored energy is much higher, giving a critical radius generally less than $10 \mu \mathrm{m}$ (Gottstein, 2004).

Calculations based on nucleation theory involving thermal fluctuations (Christian, 1965) indicate that the radius of the critical nucleus is so large that the rate of nucleation will be negligible. It is therefore accepted that the nucleation step is associated with instability of the dislocation microstructure within original grains (Humphreys and Hatherly, 1996; Bréchet and Martin, 2006). Recrystallization at preexisting high-angle boundaries is known to be a very important process since it implies low strain and high temperature. Strain-induced grain boundary migration involves the bulging of part of the grain boundary due to different stored energies on opposite sides of the boundary (Humphreys and Hatherly, 1996).

Grain nucleation during dynamic recrystallization in ice was recently analyzed by considering the interaction of a nucleating grain with the long-range internal stress field that develops during primary creep (Duval and others, arxiv.org/pdf/1007.4878). We suggest that long-range internal stresses may significantly reduce the size of the critical nucleus because grain nucleation relaxes this internal stress field over a distance much higher than the embryo. As a consequence, the free energy associated with grain nucleation includes an additional energy corresponding to the reduction of dislocation density outside the embryo. Taking into account the rearrangement of dislocation pile-ups following the absorption of leading dislocations by a dislocation-free embryo allows the critical radius to be very small and the energy of the embryo to decrease continuously with increasing size. Both situations with and without a critical stored energy to initiate grain nucleation are shown in Figure 6. The main assumption in this theoretical analysis is that much of the energy needed to form a new grain comes from the relaxation of long-range internal stresses associated with the nucleation of a new grain. The low critical strain, $\varepsilon_{\mathrm{c}}$ (of $\sim 1 \%$ ), required to initiate dynamic migration recrystallization in ice could be explained by these processes and therefore be associated with large strain and stress heterogeneities in the polycrystal.

\subsection{Dynamic discontinuous recrystallization fabrics in glaciers and ice sheets}

Dynamic discontinuous recrystallization in ice induces fabrics that are very different from deformation fabrics. As observed in temperate glaciers (Rigsby, 1951) and in the laboratory (Steinemann, 1958; Kamb, 1972; Duval, 1981; Jacka and Maccagnan, 1984), most crystals are well oriented for basal slip. In uniaxial compression, a girdle fabric develops around the compression axis, with $c$-axes at $\sim 30^{\circ}$ from the compression axis (Jacka and Maccagnan, 1984), whereas slip induces a fabric with most of the $c$-axes around the compression direction. In polar ice sheets, recrystallization fabrics may not contain orientations present in deformation textures. Figure 7 shows the microstructure of ice from the Antarctic Talos Dome ice core at $1171 \mathrm{~m}$ depth and the orientation of $c$-axes. Most grains are oriented along the vertical direction, which can be assumed parallel to the in situ compression axis. The orientation of the few large grains, probably induced by discontinuous recrystallization, appears to be very far from the orientation of the other grains, due to the rotation of the lattice by basal slip. 

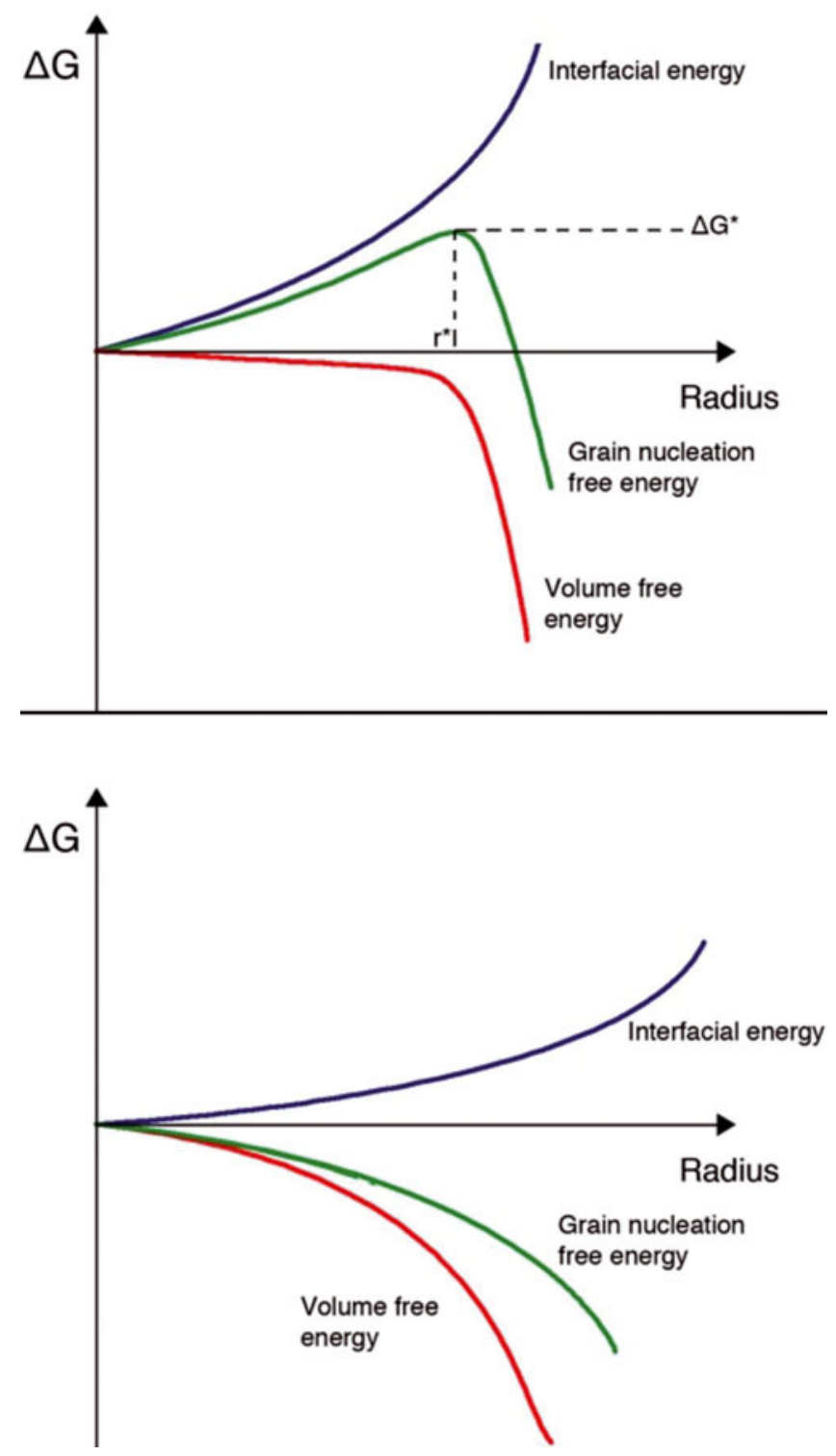

Fig. 6. Schematic free energy of formation of a nucleus as a function of the nucleus size: (top) with $\Delta g=\frac{4}{3} \pi r^{3}\left(\Delta g_{\mathrm{v}}\right)+4 \pi r^{2} \gamma_{\mathrm{gb}}$, and (bottom) by taking into account the effect of long-range internal stresses.

Discontinuous recrystallization therefore seems to be associated with the development of grains with orientations outside the spread of orientations corresponding to deformation fabrics. This situation, for which continuous and discontinuous recrystallization coexist at the same depth, is in agreement with the instability in the grain boundary migration rate as described by Guillopé and Poirier (1979). Grain nucleation by subgrain rotation and grain nucleation by local strain-induced grain boundary migration are wellaccepted mechanisms for continuous recrystallization. However, they cannot be at the origin of fabrics that form during discontinuous recrystallization since the orientation of new grains should reflect the orientation of the parent grains. Grain nucleation in the presence of large orientation gradients could give grains with orientations different from those of parents, but they should inherit their orientation from them. The stress-controlled orientation pattern associated with discontinuous dynamic recrystallization in ice (Duval, 1981) clearly rules out a direct relation between the
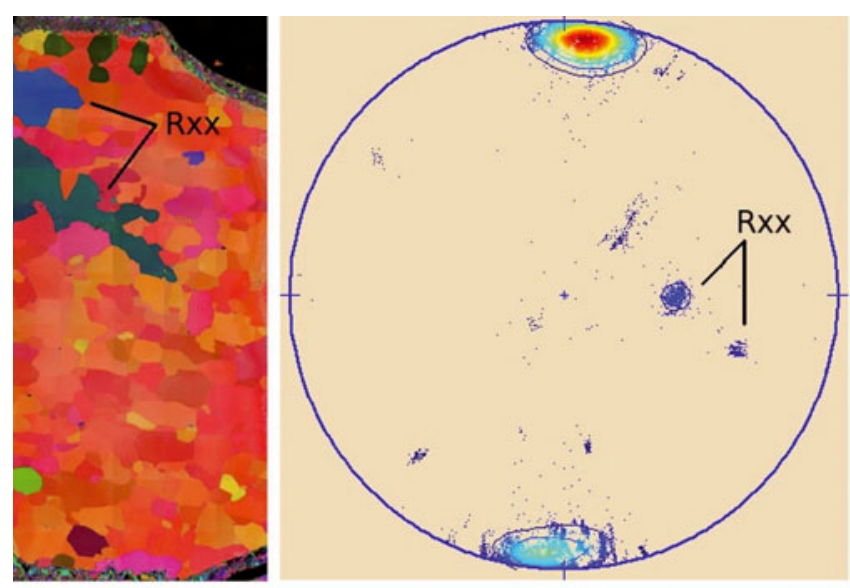

Talos Dome ice core $1171 \mathrm{~m}$

Fig. 7. Fabric of an ice sample from the Talos Dome ice core; Rxx shows the correspondence between the ice texture and fabric for two grains. Talos Dome is on the edge of the East Antarctic plateau $\left(72^{\circ} 47^{\prime} \mathrm{S}, 159^{\circ} 04^{\prime} \mathrm{E} ; 2318 \mathrm{ma.s.I}\right.$ ); a $1620 \mathrm{~m}$ ice core was recovered in 2007 (Urbini and others, 2008).

orientation of grains before and after dynamic discontinuous recrystallization.

The role of internal stresses in the nucleation of grains, as assumed above, could be important in the development of these stress-controlled textures. The long-range internal stress field is modified and relieved by the continuous nucleation and growth of grains. On the other hand, as discontinuous recrystallization produces grains well oriented for basal slip, the density of excess dislocations during recrystallization, i.e. those that accommodate long-range internal stresses, should be lower than that expected before recrystallization starts. Recrystallization textures could therefore be seen as those that minimize the long-range internal stress field.

\section{MODELING APPROACHES}

Efforts to simulate the mechanical behavior of ice polycrystals aim at modeling ice flow and fabric evolution along polar ice cores. More recently, ice has been recognized as a 'model material' for validating micro-macro full-field modeling approaches for extreme visco-plastic anisotropy.

Castelnau and others (1997) first applied the visco-plastic self-consistent (VPSC) scheme to ice polycrystals to characterize the relation between the texture of the material and the instantaneous anisotropic mechanical behavior. The VPSC approach, which has been widely used for ice viscoplastic behavior modeling, is a micro-macro approach which seeks to derive, according to active deformation mechanisms, an interaction equation that links microscopic state (stress and strain rate at the grain scale) with the macroscopic state (the polycrystal scale) (Lebensohn and Tomé, 1993). The grain inside the polycrystal is represented by an inclusion in a homogeneous equivalent medium, whose mechanical behavior is that of the polycrystal. This is currently referred to as a 'one-site' scheme.

Such a homogenization method is based on several approximations. In order to deal with the nonlinearity of the relation between the strain rate and stress (with a stress exponent of 3 for ice), the VPSC approach is based on 
linearization schemes bounded by the static estimate (uniform stress in all grains) and the Taylor estimate (uniform strain rate). The tangent approach, used by Castelnau and others $(1996 b, 1997)$ to represent the mechanical behavior of anisotropic ice or to model the fabric evolution along ice core, was recently shown to be not well adapted for representing the behavior of highly anisotropic materials (Lebensohn and others, 2004). Since then, a second-order approach, which considers the second moment of stress and strain rate in order to obtain the local linearized behavior, was shown to better represent the mechanical behavior of ice (Liu and Ponte Castañeda, 2004).

The visco-plastic modeling requires knowledge of the constitutive relation at the single-crystal scale. In particular, the grain scale deformation comes from slip on several slip systems whose local activity depends on the Schmidt factor, a critical resolved shear stress (CRSS) and a possible hardening law for every slip system. In the case of ice, very little evidence exists of slip on non-basal systems. Nevertheless, four systems are required in the self-consistent scheme to enable all possible deformations (Hutchinson, 1976). Prismatic and pyramidal slip systems are then used and their relative activity is regulated via the CRSS and its evolution with a parameterized hardening law if necessary. The values, which are model-dependent, can be adjusted with mechanical test results using inverse methods (Castelnau and others, 1997). Doing so, good estimates of the behavior of isotropic or strongly textured ice could be reproduced.

The tangent approach was applied by Castelnau and others (1996a) to model the fabric evolution along the Greenland Icecore Project (GRIP) ice core, the 'dome-like' configuration of which allowed the assumption of deformation under compression at a constant strain rate. The model provided predictions in good agreement with measurements in the upper $650 \mathrm{~m}$ of the core, but predicted fabrics below $650 \mathrm{~m}$ were too concentrated. Dynamic continuous recrystallization mechanisms, which were not considered in the modeling approach, were supposed to explain most of the discrepancy, but a nearest-neighbor interaction scheme associated with a static estimate gave a better result (Thorsteinsson, 2002). Stress redistribution within the polycrystal could also be indirectly taken into account by integrating the intragranular stress and strainrate fields in the VPSC linearization procedure as made possible by the second-order approach (Liu and Ponte Castañeda, 2004). This approach predicts a quasi-persistent accommodation of deformation by basal slip, even when the $c$-axes become strongly aligned with the compression axis (Lebensohn and others, 2007). Furthermore, a very good match with measured fabric evolution along the Antarctic EPICA Dome C core is obtained by applying a uniaxial compression at a constant rate as long as migration recrystallization does not occur (Fig. 8).

More recently, the full-field formulation based on FFTs from Lebensohn (2001) was used to predict the micromechanical fields that develop in 2-D columnar ice polycrystals deforming in compression (Lebensohn and others, 2009). This micro-macro approach allows solution of the governing mechanical behavior on every point of a Fourier grid which discretizes the polycrystal represented as a representative volume element (RVE). The RVE polycrystal is then periodized in order to solve the constitutive equations in the Fourier space. Doing so, mechanical fields

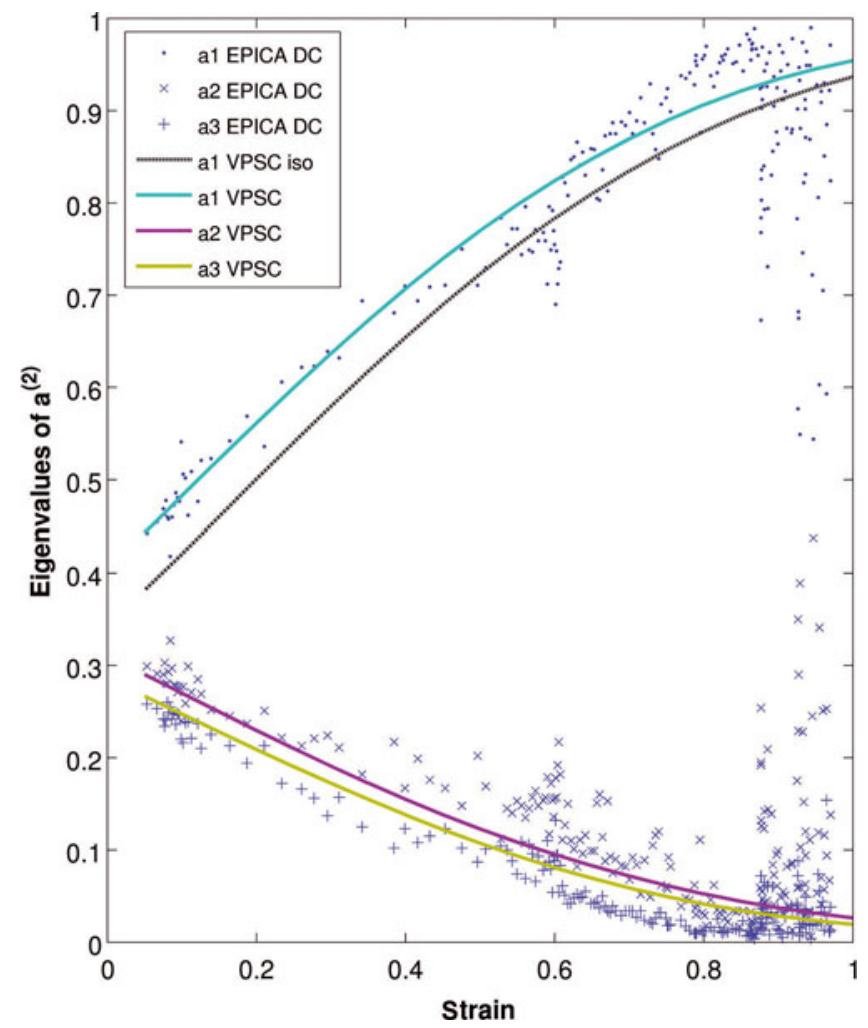

Fig. 8. VPSC second-order prediction of fabric evolution along the EPICA Dome C ice core (expressed via the eigenvalues of orientation tensor $a^{(2)}$ (from Durand and others, 2006), compared with measurements (Durand and others, 2009). Solid curves represent an anisotropic initial fabric, the dashed curve an isotropic one. Symbols plot the measured $a^{(2)}$ eigenvalues.

can be obtained at an intragranular scale very similarly to finite-element approaches but at a much lower computational cost. As shown in Figure 9, the model predicts very well the location of strain concentration (strain-rate field maps), in comparison with measured strain field using digital image correlation techniques on '2-D' columnar ice samples deformed by compression creep up to $1 \%$ strain (Grennerat and others in press).

\section{CONCLUSIONS}

This work attempts to show the essential role of long-range dislocation interactions in the plastic behavior of ice single crystals and polycrystals, and stresses the role of ice as a model material to analyze this important topic from a more generic point of view.

The intermittent and scale-free nature of plastic flow in materials was revealed by acoustic emission studies in ice crystals. Strain bursts produced by dislocation avalanches are triggered by long-range interaction stresses between dislocations and should contribute to the essential part of the macroscopic strain in single crystals. There is a direct connection between avalanches and the formation of dislocation patterns in the form of slip lines or slip bands, which exhibit long-range spatial correlations. Dislocation multiplication by cross-slip is suggested in spite of the expected dissociation of basal dislocations.

Primary creep in polycrystals is analyzed by considering directional hardening induced by slip incompatibility 


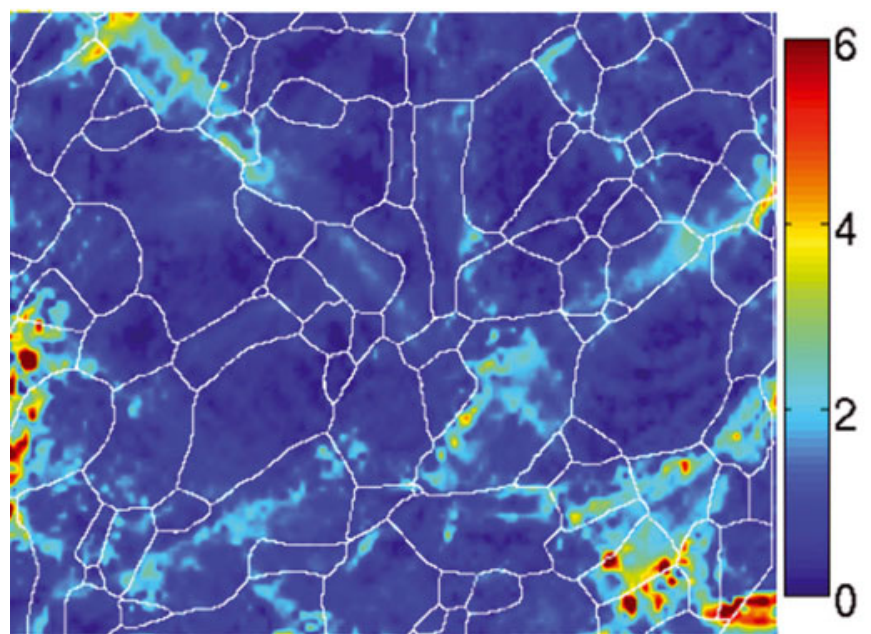

a

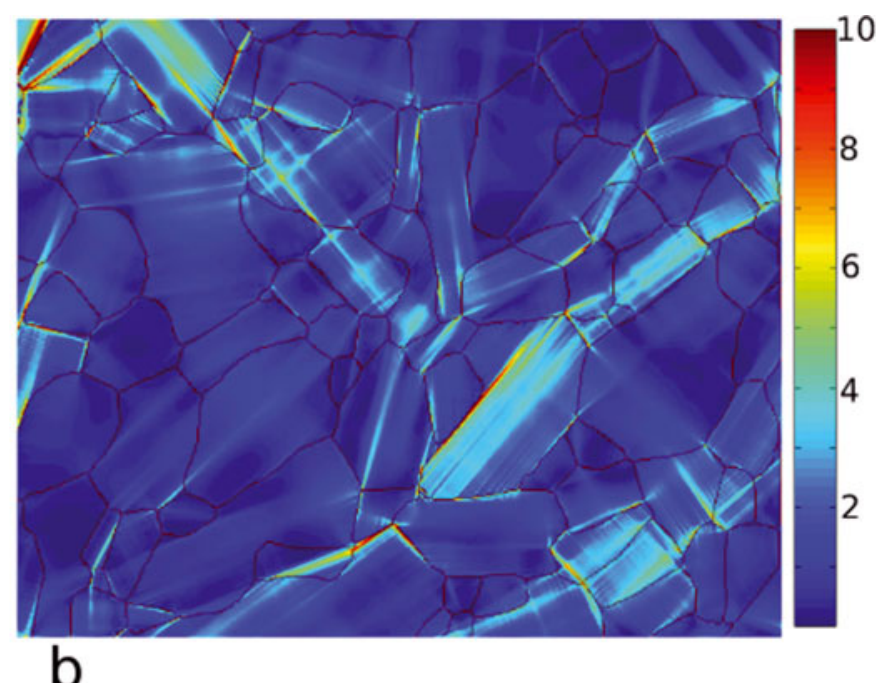

Fig. 9. Comparison between (a) measured equivalent strain field in columnar ice and (b) simulated strain-rate field using the full-field viscoplastic FFT approach. In both cases, values are normalized by the average.

between grains and softening by climb or cross-slip of basal dislocations. Both processes involve a large number of interacting dislocations. Based on experimental measurements and simulations of the mechanical behavior, it is shown that very large stress and strain intragranular heterogeneities build up with deformation. They are responsible for initiating dynamic recrystallization for a relatively low critical strain. Grain nucleation during discontinuous recrystallization is analyzed by considering the relaxation of long-range internal stresses, occurring as soon as an embryo forms. With this additional driving force, a negligible critical free energy for the formation of a nucleus could be obtained. This assumption, if confirmed, gives an original view of grain nucleation during dynamic recrystallization in ice, but also in other materials. In this context, stress-controlled fabrics in glaciers and polar ice sheets can be understood.

Ice is thus a marvelous material which warrants many years of study by ice glaciologists and geophysicists. It is now also considered a model material for understanding deformation processes in metals, and for polycrystal modelling.

\section{ACKNOWLEDGEMENTS}

We are grateful to the International Glaciological Society for inviting this contribution, and to G.K.C. Clarke and a reviewer for their encouragement. This work was supported by CNRS (Institut des Sciences de I'Ingénierie et des Systèmes (INSIS)) and the Université Joseph Fourier, Grenoble, France. We thank PhD students a part of whose work is described in this paper. We gratefully acknowledge C. de Loustal and P. Fabry for the preparation of figures.

\section{REFERENCES}

Alley, R.B. 1992. Flow-law hypotheses for ice-sheet modeling. J. Glaciol., 38(129), 245-256.

Ashby, M.F. 1970. The deformation of plastically non-homogeneous materials. Philos. Mag., 21(8), 399-424.
Ashby, M.F. and P. Duval. 1985. The creep of polycrystalline ice. Cold Reg. Sci. Technol., 11(3), 285-300.

Barnes, P., D. Tabor and J.C.F. Walker. 1971. The friction and creep of polycrystalline ice. Proc. R. Soc. London, Ser. A, 324(1557), 127-155.

Bréchet, Y. and G. Martin. 2006. Nucleation problems in metallurgy of the solid state: recent developments and open questions. C. R. Phys., 7(9-10), 959-976.

British Glaciological Society (BGS). 1949. Joint meeting of the British Glaciological Society, the British Rheologists' Club and the Institute of Metals. J. Glaciol., 1(5), 231-240.

Budd, W.F. and T.H. Jacka. 1989. A review of ice rheology for ice sheet modelling. Cold Reg. Sci. Technol., 16(2), 107-144.

Castelnau, O., T. Thorsteinsson, J. Kipfstuhl, P. Duval and G.R. Canova. 1996a. Modelling fabric development along the GRIP ice core, central Greenland. Ann. Glaciol., 23, 194-201.

Castelnau, O., P. Duval, R. Lebensohn and G.R. Canova. 1996b. Viscoplastic modeling of texture development in polycrystalline ice with a self-consistent approach: comparison with bound estimates. J. Geophys. Res., 101(B6), 13,851-13,868.

Castelnau, O., G.R. Canova, R.A. Lebensohn and P. Duval. 1997. Modelling viscoplastic behavior of anisotropic polycrystalline ice with a self-consistent approach. Acta Mater., 45(11), 4823-4834.

Castelnau, O., P. Duval, M. Montagnat and R. Brenner. 2008. Elastoviscoplastic micromechanical modeling of the transient creep of ice. J. Geophys. Res., 113(B11), B11203. (10.1029/ 2008JB005751.)

Chevy, J., C. Fressengeas, M. Lebyodkin, V. Taupin, P. Bastie and P. Duval. 2010. Characterizing short-range vs. long-range spatial correlations in dislocation distributions. Acta Mater., 58(5), 1837-1849.

Christian, J.W. 1965. The theory of transformations in metals and alloys. Oxford, etc., Pergamon Press.

Cuffey, K.M. and W.S.B. Paterson. 2010. The physics of glaciers. Fourth edition. Oxford, Butterworth-Heinemann.

De La Chapelle, S., O. Castelnau, V. Lipenkov and P. Duval. 1998. Dynamic recrystallization and texture development in ice as revealed by the study of deep ice cores in Antarctica and Greenland. J. Geophys. Res., 103(B3), 5091-5105.

Dimiduk, D.M., C. Woodward, R. Le Sar and M.D. Uchic. 2006. Scale-free intermittent flow in crystal plasticity. Science, 312(5777), 1188-1190. 
Duesbery, M.S. 1998. Dislocation motion, constriction and crossslip in fcc metals. Model. Simulat. Mater. Sci. Eng., 6(1), 35-49.

Durand, G., O. Gagliardini, T. Thorsteinsson, A. Svensson, J. Kipfstuhl and D. Dahl-Jensen. 2006. Ice microstructure and fabric: an up-to-date approach for measuring textures. J. Glaciol., 52(179), 619-630.

Durand, G. and 7 others. 2009. Evolution of the texture along the EPICA Dome C ice core. In Hondoh, T., ed. Physics of ice core records II. Hokkaido, Hokkaido University. Institute of Low Temperature Science, 91-106. (Low Temp. Sci., 68, Suppl. issue.)

Durham, W.B., S.H. Kirby and L.A. Stern. 1992. Effects of dispersed particulates on the rheology of water ice at planetary conditions. J. Geophys. Res., 97(E12), 20,883-20,897.

Duval, P. 1978. Anelastic behaviour of polycrystalline ice. J. Glaciol., 21(85), 621-628.

Duval, P. 1981. Creep and fabrics of polycrystalline ice under shear and compression. J. Glaciol., 27(95), 129-140.

Duval, P. and O. Castelnau. 1995. Dynamic recrystallization of ice in polar ice sheets. J. Phys. IV [Paris], 5(C3), 197-205.

Duval, P., M.F. Ashby and I. Anderman. 1983. Rate-controlling processes in the creep of polycrystalline ice. J. Phys. Chem., 87(21), 4066-4074.

Glen, J.W. 1952. Experiments on the deformation of ice. J. Glaciol., 2(12), 111-114.

Glen, J.W. 1955. The creep of polycrystalline ice. Proc. R. Soc. London, Ser. A, 228(1175), 519-538.

Glen, J.W. and M.F. Perutz. 1954. The growth and deformation of ice crystals. J. Glaciol., 2(16), 397-403/395-396.

Gottstein, G. 2004. Physical foundations of materials science. Berlin, etc., Springer.

Grennerat, F., M. Montagnat, O. Castelnau, P. Vacher and P. Duval. In press. Intragranular strain field in columnar ice during transient creep regime and relation with the local microstucture. In Proceedings of the 14th International Conference on Experimental Mechanics (ICEM 14), 4-9 July 2010, Poitiers, France.

Griggs, D.T. and N.E. Coles. 1954. Creep of single crystals of ice. SIPRE Rep. 11.

Guillopé, M. and J.P. Poirier. 1979. Dynamic recrystallization during creep of single-crystalline halite: an experimental study. J. Geophys. Res., 84(B10), 5557-5567.

Higashi, A. 1967. Mechanisms of plastic deformation in ice single crystals. In Oura, H., ed. Physics of snow and ice. Sapporo, Hokkaido University. Institute of Low Temperature Science, 277-289.

Higashi, A., S. Koinuma and S. Mae. 1965. Bending creep of ice single crystals. Jpn. J. Appl. Phys., 4(8), 575-582.

Humphreys, F.J. and M. Hatherly. 1996. Recrystallization and related annealing phenomena. Oxford, Pergamon.

Hutchinson, J.W. 1976. Bounds and self-consistent estimates for creep of polycrystalline materials. Proc. R. Soc. London, Ser. A, 348(1652), 101-127.

Jacka, T.H. 1984. The time and strain required for development of minimum strain rates in ice. Cold Reg. Sci. Technol., 8(3), 261-268.

Jacka, T.H. and M. Maccagnan. 1984. Ice crystallographic and strain rate changes with strain in compression and extension. Cold Reg. Sci. Technol., 8(3), 269-286.

Jones, S.J. and J.W. Glen. 1969. The mechanical properties of single crystals of pure ice. J. Glaciol., 8(54), 463-473.

Kamb, B. 1972. Experimental recrystallization of ice under stress. In Heard, H.C., I.Y. Borg, N.L. Carter and C.B. Raleigh, eds. Flow and fracture of rocks. Washington, DC, American Geophysical Union, 211-241. (Geophysical Monograph 16.)

Lebensohn, R.A. 2001. N-site modeling of a 3D viscoplastic polycrystal using Fast Fourier Transform. Acta Mater., 49(14), 2723-2737.

Lebensohn, R.A. and C.N. Tomé. 1993. A self-consistent anisotropic approach for the simulation of plastic deformation and texture development of polycrystals: application to zirconium alloys. Acta Metall., 41(9), 2611-2624.

Lebensohn, R.A., Y. Liu and P. Ponte Castañeda. 2004. On the accuracy of the self-consistent approximation for polycrystals: comparison with full-field numerical simulations. Acta Mater., 52(18), 5347-5361.

Lebensohn, R.A., C.N. Tomé and P. Ponte Castañeda. 2007. Selfconsistent modelling of the mechanical behaviour of viscoplastic polycrystals incorporating intragranular field fluctuations. Philos. Mag., 87(28), 4287-4322.

Lebensohn, R.A., M. Montagnat, P. Mansuy, P. Duval, J. Meyssonnier and A. Philip. 2009. Modeling viscoplastic behavior and heterogeneous intracrystalline deformation of columnar ice polycrystals. Acta Mater., 57(5), 1405-1415.

Liu, Y. and P. Ponte Castañeda. 2004. Second-order theory for the effective behavior and field fluctuations in viscoplastic polycrystals. J. Mech. Phys. Solids, 52(2), 467-495.

Louchet, F. and P. Duval. 2009. Andrade creep revisited. Int. J. Mater. Res., 100(10), 1433-1439.

Ma, Y., O. Gagliardini, C. Ritz, F. Gillet-Chaulet, G. Durand and M. Montagnat. 2010. Enhancement factors for grounded ice and ice shelves inferred from an anisotropic ice-flow model. J. Glaciol., 56(199), 805-812.

Mansuy, P. 2001. Contribution à l'étude du comportement viscoplastique d'un multicristal de glace: hétérogénéité de la déformation et localisation, expériences et modèles. (PhD thesis, Université Joseph Fourier.)

Martín, C., G.H. Gudmundsson, H.D. Pritchard and O. Gagliardini. 2009. On the effects of anisotropic rheology on ice flow, internal structure, and the age-depth relationship at ice divides. J. Geophys. Res., 114(F4), F04001. (10.1029/ 2008JF001204.)

McConnel, J.C. and D.A. Kidd. 1888. On the plasticity of glacier and other ice. Proc. R. Soc. London, Ser. A, 44(270), 331-367.

Mellor, M. and R. Testa. 1969. Creep of ice under low stress. J. Glaciol., 8(52), 147-152.

Mendelson, S. 1963. Glide band formation and broadening in ionic single crystals. Philos. Mag., 8(94), 1633-1648.

Miguel, M.-C., A. Vespignani, S. Zapperi, J. Weiss and J.-R. Grasso. 2001. Intermittent dislocation flow in viscoplastic deformation. Nature, 410(6829), 667-671.

Miguel, M.-C., A. Vespignani, M. Zaiser and S. Zapperi. 2002. Dislocation jamming and Andrade creep. Phys. Rev. Lett., 89(16), 165501. (10.1103/PhysRevLett.89.165501.)

Montagnat, M. and P. Duval. 2000. Rate controlling processes in the creep of polar ice: influence of grain boundary migration associated with recrystallization. Earth Planet. Sci. Lett., 183(1-2), 179-186.

Montagnat, M. and 6 others. 2006. The heterogeneous nature of slip in ice single crystals deformed under torsion. Philos. Mag., 86(27), 4259-4270.

Mott, N.F. 1953. A theory of work-hardening of metals II: flow without slip-lines, recovery and creep. Philos. Mag., Ser. 7, 44(354), 742-765.

Nakaya, U. 1958. Mechanical properties of single crystals of ice. Part 1. Geometry of deformation. SIPRE Res. Rep. 28.

Nye, J.F. 1952. The mechanics of glacier flow. J. Glaciol., 2(12), 82-93.

Nye, J.F. 1953. Some geometrical relations in dislocated crystals. Acta Metall., 1(2), 153-162.

Orowan, E. 1940. Problems of plastic gliding. Proc. Phys. Soc. [London], 52(1), 8-22.

Orowan, E. 1946. The creep of metals. J. West Scot. Iron Steel Inst., 54, 45-96.

Paterson, W.S.B. 1991. Why ice-age ice is sometimes 'soft'. Cold Reg. Sci. Technol., 20(1), 75-98.

Petrenko, V.F. and R.W. Whitworth. 1999. Physics of ice. Oxford, etc., Oxford University Press. 
Poirier, J.P. 1985. Creep of crystals. Cambridge, etc., Cambridge University Press.

Rendu, L. 1840. Théorie des glaciers de la Savoie. Chambéry, Chez Puthod. (Mémoire de l'Académie des Sciences, Belles-Lettres et Arts de Savoie 10.)

Richeton, T., J. Weiss and F. Louchet. 2005a. Breakdown of avalanche critical behaviour in polycrystalline plasicity. Nature Mater., 4, 465-469.

Richeton, T., J. Weiss and F. Louchet. 2005b. Dislocation avalanches: role of temperature, grain size and strain hardening. Acta Mater., 53(16), 4463-4471.

Rigsby, G.P. 1951. Crystal fabric studies on Emmons Glacier, Mount Rainier, Washington. J. Geol., 59(6), 590-598.

Roberts, W. and B. Ahlblom. 1978. A nucleation criterion for dynamic recrystallization during hot working. Acta Metall., 26(5), 801-813.

Rosti, J., J. Koivisto, L. Laurson and M.J. Alava. 2010. Fluctuations and scaling in creep deformation. Phys. Rev. Lett., 105(10), 100601. (10.1103/PhysRevLett.105.100601.)

Schulson, E.M. and P. Duval. 2009. Creep and fracture of ice. Cambridge, etc., Cambridge University Press.

Steinemann, S. 1954. Results of preliminary experiments on the plasticity of ice crystals. J. Glaciol., 2(16), 404-413.

Steinemann, S. 1958. Experimentelle Untersuchungen zur Plastizität von Eis. Beitr Geol. Schweiz. 10.

Thorsteinsson, T. 2002. Fabric development with nearest-neighbour interaction and dynamic recrystallization. J. Geophys. Res., 107(B1), 2014. (10.1019/2001JB000244.)
Thorsteinsson, T., J. Kipfstuhl and H. Miller. 1997. Textures and fabrics in the GRIP ice core. J. Geophys. Res., 102(C12), 26,583-26,599.

Tyndall, J. 1873. Les glaciers et les transformations de l'eau. Paris, Librairie Germer Baillière.

Urbini, S. and 6 others. 2008. Historical behaviour of Dome C and Talos Dome (East Antarctica) as investigated by snow accumulation and ice velocity measurements. Global Planet. Change, 60(3-4), 576-588.

Weertman, J. 1973. Creep of ice. In Whalley, E., S.J. Jones and L.W. Gold, eds. Physics and chemistry of ice. Ottawa, Ont., Royal Society of Canada, 320-337.

Weertman, J. 1983. Creep deformation of ice. Annu. Rev. Earth Planet. Sci., 11, 215-240.

Weiss, J. and J.-R. Grasso. 1997. Acoustic emission in single crystals of ice. J. Phys. Chem. B, 101(32), 6113-6117.

Weiss, J. and D. Marsan. 2003. Three-dimensional mapping of dislocation avalanches: clustering and space/time coupling. Science, 299(5603), 89-92.

Weiss, J. and M. Montagnat. 2007. Long-range spatial correlations and scaling in dislocation and slip patterns. Philos. Mag., 87(8-9), 1161-1174.

Zaiser, M. 2006. Scale invariance in plastic flow of crystalline solids. Adv. Phys., 55(1-2), 185-245.

Zaiser, M. and A. Seeger. 2002. Long-range internal stresses, dislocation patterning and work-hardening in crystal plasticity. In Nabarro, F.R.N., M.S. Duesbery and J. Hirth, eds. Dislocations in solids, Vol. 11. Amsterdam, North-Holland, 1-100. 